\title{
DETERMINAÇÃO DA QUALIDADE E DO TEOR DE SÓLIDOS SOLÚVEIS NAS DIFERENTES PARTES DO FRUTO DA PINHEIRA (Annona squamosa L.) ${ }^{1}$
}

\author{
JAEVESON DA SILVA², ELIVÂNIA SOARES DA SILVA ${ }^{3}$ PAULO SÉRGIO LIMA E SILVA ${ }^{4}$
}

\begin{abstract}
RESUMO - O objetivo foi avaliar algumas características qualitativas e estimar o teor de sólidos solúveis (TSS) nas porções basal (ligada ao pedúnculo), mediana e apical do fruto da pinheira. Para a estimação desse teor, três pinhas de cada uma de dez árvores, de pomares localizados em Mossoró-RN e Aracati-CE, com idade entre seis e oito anos, foram utilizadas. As árvores foram consideradas repetições (blocos), os frutos foram considerados parcelas e as porções dos frutos, subparcelas. Três frutos de cada árvore foram descascados e divididos em três porções aproximadamente iguais, da base para o ápice. O material foi triturado e filtrado. No suco obtido, foram feitas três leituras em um refratômetro. A média destas três leituras representou o valor de cada subparcela. A análise de variância conjunta indicou efeitos de locais, blocos em locais, porções e da interação locais $\mathrm{x}$ frutos $\mathrm{x}$ porções. O peso do fruto variou de 226 a 418 g e o rendimento de polpa, de 45 a $54 \%$. O TSS na porção basal (26,49\%) foi inferior aos teores das porções mediana (28,02 $\%)$ e apical $(27,53 \%)$, mas não diferiu significativamente daquele da porção apical.
\end{abstract}

Termos de indexação: pinha, ata, brix, frutos tropicais, fruta-do-conde.

\section{DETERMINATION OF THE QUALITY AND SOLUBLE SOLIDS CONTENT AT DIFFERENT PARTS OF CUSTARD APPLE (Annona squamosa L.) FRUIT}

\begin{abstract}
The objective of this research was evaluate some qualitative traits and estimate the soluble solids content (SSC) in basal (linked to peduncle), median and apical fractions of the custard apple. Three fruits of each one of the ten trees, from 6-8 years old, orchards growing at Mossoró-RN and Aracati-CE, Brazil were utilized. The trees were considered replications (blocks), the fruits were the plots and the fruit fractions were the subplot. Three fruits of each tree were peeled and fractioned in the mentioned portions. The material was homogenized in a blender and filtered in nylon. In the juice obtained, three readings in a digital refractometer were made. The average of these values represented the value for each splitplot. The joint analysis of variance showed effects of sites, blocks whitin sites, fractions and sites $\mathrm{x}$ fruits $\mathrm{x}$ fractions interaction. The fruit weight varied 226 to $418 \mathrm{~g}$ and the pulp yield (pulp weight/fruit weight) varied of 45 to $54 \%$. The SSC in basal fraction $(26.49 \%)$ was lower than in the median (28.02\%) and in the apical $(27.53 \%)$ portions contents, but did not differ significantly from that to the apical fraction.
\end{abstract}

Index terms: sugar apple, tropical fruits.

No Nordeste brasileiro, a pinha é comercializada para o consumo "in natura" ou para o preparo de sucos e sorvetes (Carvalho et al., 2000). O interesse pela exploração da pinha com irrigação nessa região tem crescido porque existe interesse na exploração de um maior número de espécies, visando à retenção de mão-de-obra e à redução dos problemas de doenças e pragas, que ocorrem com mais freqüência nas monoculturas. Além disso, com o aperfeiçoamento dos meios de comunicação e de transporte, estão surgindo novos e amplos mercados para uma grande gama de frutos tropicais e subtropicais.

O teor de sólidos solúveis é um parâmetro que tem sido usado como indicador da qualidade dos frutos, incluindo melão (Grangeiro et al., 1999) e pinha (Maia et al., 1986), dentre outros. O teor de sólidos solúveis é de grande importância nos frutos, tanto para o consumo "in natura" como para o processamento industrial, visto que elevados teores desses constituintes na matéria-prima implicam menor adição de açucares, menor tempo de evaporação da água, menor gasto de energia e maior rendimento do produto, resultando em maior economia no processamento (Pinheiro et al., 1984). Métodos baseados em espectroscopia têm sido usados para a avaliação do teor de sólidos solúveis em vários tipos de frutos (Martinsen e Schaare, 1998). Contudo, os métodos destrutivos, isto é, baseados no processamento do material e posterior uso do refratômetro ainda são os mais usados (Maia et al., 1986; Granjeiro et al., 1999) por serem simples, baratos e fáceis de serem empregados. No uso de tais métodos, a porção do fruto a ser avaliada deve ser obtida de tal maneira que o teor de sólidos solúveis nela determinado re-

1 (Trabalho 095/2001). Recebido: 23/05/2001. Aceito para publicação: 02/05/2002.

2 Engo ${ }^{\circ}$ Agro , estudante do curso de Mestrado em Fitotecnia da Esc. Sup. Agric. Mossoró (ESAM). Cx. Postal 137 - 59625-900 Mossoró-RN. Fone: (084) 321-2403. E-mail: jaeveson@bol.com.br

3 Eng ${ }^{\mathrm{o}} \mathrm{Agr}^{\mathrm{o}}$, estudante do curso de Mestrado em Fitotecnia da ESAM. Cx. Postal 137 - 59625-900 - Mossoró-RN. Fone: (084) 3174073. E-mail: elivaniasoares@bol.com.br

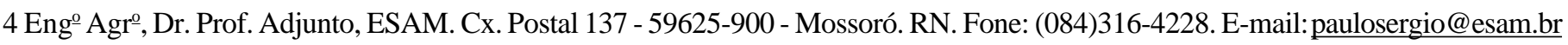

Rev. Bras. Frutic., Jaboticabal - SP, v. 24, n. 2, p. 562-564, agosto 2002 
presente o teor de todo o fruto. Em alguns tipos de frutos, isto é importante, mesmo para o agricultor. Por exemplo, para ser exportado, o melão necessita ter um teor de sólidos solúveis mínimo de $8 \%$ caso o mercado importador seja o europeu. No caso do mercado norte-americano, este valor passa a ser de $9 \%$ (Bleinroth, 1994). Desta maneira, a determinação do teor de sólidos solúveis passa a ser uma atividade rotineira entre agricultores.

Apenas dois trabalhos (Araújo, 1986; Simão \& Pimentel Gomes, 1996) sobre o assunto foram encontrados na literatura consultada. Araújo (1086) constatou variabilidade da percentagem de sólidos solúveis no bulbo da cebola. De modo semelhante, Simão \& Pimentel-Gomes (1996) verificaram diferenças nas distribuições de açúcares e acidez no fruto da mangueira (Mangifera indica L.)

O objetivo do presente trabalho foi estimar o teor de sólidos solúveis em três frações do fruto da pinheira, bem como a determinação de sua qualidade

Em junho de 2000, foram colhidos três frutos de cada uma de dez árvores de dois pomares (cinco árvores em cada pomar), sendo um localizado em Mossoró-RN e o outro em Aracati-CE. As árvores, com seis a oito anos de idade, e obtidas a partir de sementes, identificadas daqui por diante por Aracati1, e Mossoró-5, foram selecionadas com base em rendimento de frutos, sanidade e vigor, e forneceram sementes para serem utilizadas em trabalhos de melhoramento genético. Os frutos foram colhidos em estádio próximo ao de consumo e neles, dois a três dias depois de armazenamento sob condições ambientais, foram avaliados o tamanho, o diâmetro máximo, os pesos total, do pericarpo, do total de sementes e da polpa, e o rendimento de polpa (peso da polpa/peso total do fruto). Depois de descascados, os frutos foram divididos em três partes aproximadamente iguais, tomando-se a altura como base para divisão, obtendo-se frações denominadas, daqui por diante, de basal (ligada ao pedúnculo), mediana e apical. Após a retirada das sementes, a polpa (mesocarpo + endocarpo) foi triturada em pilão de alumínio, e o material resultante filtrado em tecido de nailon. Três gotas do suco obtido em cada fração foram usadas para realização de cada uma de três determinações do teor de sólidos solúveis, em refratômetro digital.

Foram feitas análises de variância individual e conjunta. Cada planta foi considerada um bloco, e os tratamentos foram combinados em parcelas subdivididas, isto é, os frutos foram considerados parcelas e as porções, subparcelas. Na análise conjunta, os 89 graus de liberdade foram desdobrados em: 1 grau para locais (L) (pomares), 8 graus para blocos (plantas) dentro de locais, 2 graus para frutos $(\mathrm{F}), 2$ graus para a interação L x F, 16 graus para o resíduo (a), 2 graus para porções do fruto $(\mathrm{P})$, dois graus para $\mathrm{L} \times \mathrm{P}, 4$ graus para $\mathrm{F} \times \mathrm{P}, 4$ graus para $\mathrm{L} \times \mathrm{F} x$ $\mathrm{P}$ e 48 graus para o resíduo (b) (Carmer et al., 1989).

Houve variação ampla nas características de qualidade dos frutos avaliados (Tabela 1). A altura média do fruto variou de $6,6 \mathrm{~cm}$ a $8,7 \mathrm{~cm}$, enquanto o diâmetro máximo variou de 7,8 $\mathrm{cm}$ a 10,1 cm. Maia et al. (1986), em 30 frutos adquiridos em mercado e usados para avaliação de características físicas e químicas, encontraram dimensões de 4,3 cm x 5,3 cm e de 7,4 cm x 7,8 $\mathrm{cm}$ para os frutos menores e maiores analisados, respectivamente. O peso médio dos frutos variou de $226 \mathrm{~g}$ a $418 \mathrm{~g}$. Estes valores são relativamente elevados se comparados aos valores observados por Carvalho et al. (2000) em frutos de dez matrizes de pinheira, colhidos durante um período de cinco anos (variação foi de $202 \mathrm{~g}$ a $235 \mathrm{~g}$ ). As diferenças podem ser devidas ao fato de que, no presente trabalho, os frutos foram selecionados pelo tamanho, visando-se a obter maior quantidade de sementes para trabalhos de melhoramento. Maia et al. (1986) verificaram que o peso médio dos frutos variou de $138 \mathrm{~g}$ a $393 \mathrm{~g}$, com média de 201 g. Observaram ainda que o rendimento de polpa variou de $41,8 \%$ a $65,3 \%$, com média de $54,2 \%$. No presente trabalho, o rendimento de polpa variou de $45,0 \%$ a 53,5\%. No trabalho de Maia et al. (1986), as médias de epicarpo e de sementes foram de 38,2\% e $7,6 \%$ do peso do fruto, respectivamente. Neste artigo, a percentagem média de epicarpo variou de $38,8 \%$ a 49,2\%.

A análise de variância indicou efeito significativo de locais (pomares), blocos (plantas) dentro de locais, porções e da interação locais x frutos x porções. O efeito significativo de locais significa que o teor de sólidos solúveis dos frutos do pomar de Aracati (28,90\%) foi, em média, superior ao teor dos frutos de Mossoró $(25,80 \%)$ (Tabela 2). Tanto diferenças genéticas entre plantas como diferenças ambientais explicam as diferenças entre os dois teores. O teste de Tukey não indicou diferenças entre plantas de Aracati, mas, entre as plantas de Mossoró, constatou-se que a planta 2 foi inferior às plantas 1 e 3 , em média. $O$ teor de sólidos solúveis na porção basal dos frutos foi inferior aos teores das porções mediana e apical, mas somente diferiu significativamente do teor da porção mediana. De qualquer forma, o teor de sólidos solúveis na porção apical foi maior que o teor da porção basal, desde que o da porção apical não diferiu do teor da

TABELA 1 - Médias de algumas características de três frutos de 10 pinheiras

\begin{tabular}{lcccccc}
\hline $\begin{array}{l}\text { Plantas } \\
\text { (blocos) }\end{array}$ & $\begin{array}{c}\text { Altura } \\
(\mathrm{cm})\end{array}$ & $\begin{array}{c}\text { Diâmetro } \\
\text { máximo } \\
(\mathrm{cm})\end{array}$ & $\begin{array}{c}\text { Peso médio } \\
\text { Do fruto } \\
(\mathrm{g})\end{array}$ & $\begin{array}{c}\text { Rendimento } \\
\text { de polpa } \\
(\%)\end{array}$ & $\begin{array}{c}\text { Peso médio do } \\
\text { epicarpo }(\mathrm{g})\end{array}$ & $\begin{array}{c}\text { Peso médio } \\
\text { do total de } \\
\text { sementes }(\mathrm{g})\end{array}$ \\
\hline Aracati-1 & 8,4 & 10,1 & 347,0 & 48,87 & 158,7 & 18,7 \\
Aracati-2 & 8,6 & 8,7 & 366,7 & 53,50 & 143,2 & 27,3 \\
Aracati-3 & 6,6 & 8,8 & 301,8 & 47,85 & 139,6 & 17,8 \\
Aracati-4 & 6,9 & 8,6 & 270,7 & 49,47 & 124,9 & 11,8 \\
Aracati-5 & 7,9 & 8,8 & 277,6 & 47,84 & 130,4 & 14,4 \\
Mossoró-1 & 7,2 & 8,7 & 305,5 & 45,93 & 150,3 & 14,9 \\
Mossoró-2 & 7,1 & 8,2 & 253,2 & 51,42 & 107,6 & 15,4 \\
Mossoró-3 & 7,2 & 7,8 & 226,2 & 45,03 & 113,6 & 10,7 \\
Mossoró-4 & 6,8 & 8,5 & 245,6 & 45,79 & 118,8 & 14,3 \\
Mossoró-5 & 8,7 & 9,6 & 418,1 & 51,05 & 184,0 & 20,6 \\
\hline
\end{tabular}

${ }^{1}$ Peso da polpa/peso do fruto 
TABELA 2 - Médias do teor de sólidos solúveis das frações dos frutos de 10 pinheiras. Mossoró - RN. $2000 .{ }^{1}$

\begin{tabular}{lcccc}
\hline Plantas & \multicolumn{3}{c}{ Frações dofruto } & \multirow{2}{*}{ Médias } \\
\cline { 2 - 4 } (blocos) & Basal & Mediana & Apical & 29,63 \\
Aracati-1 & 28,86 & 30,43 & 29,60 & 30,85 \\
Aracati-2 & 30,20 & 31,63 & 30,73 & 29,18 \\
Aracati-3 & 28,13 & 29,56 & 29,86 & 27,76 \\
Aracati-4 & 27,36 & 28,06 & 27,86 & 27,06 \\
Aracati-5 & 26,50 & 27,76 & 26,93 & 27,09 \\
Mossoró-1 & 25,97 & 28,33 & 26,97 & 23,14 \\
Mossoró-2 & 23,07 & 23,47 & 22,87 & 27,20 \\
Mossoró-3 & 25,40 & 27,90 & 28,30 & 25,05 \\
Mossoró-4 & 23,80 & 25,83 & 25,53 & 26,50 \\
Mossoró-5 & 25,60 & 27,23 & 26,66 & 27,33 \\
\hline Médias & $26,49 \mathrm{~b}$ & 28,02 a & 27,53 ab & \\
\hline
\end{tabular}

${ }^{1}$ Médias seguidas pela mesma letra não diferem entre si, a $5 \%$ de probabilidade, pelo teste de Tukey. (C.V.b =1,84\%)

porção mediana. Não foram encontrados, na literatura consultada, trabalhos sobre a variação do teor de sólidos solúveis nas diferentes partes da pinha. Em kiwi (Actinidia deliciosa), Martinsen \& Schaare (1998) verificaram que a concentração de sólidos solúveis na porção central do fruto foi $15 \%$ maior que nas porções interna e externa do pericarpo. Araújo (1986) observou que a percentagem de sólidos solúveis aumenta do ápice para a base e é maior nas partes internas do que nas externas do bulbo da cebola. Simão \& Pimentel-Gomes (1996) verificaram que as partes mais doces e menos ácidas foram a seção basal e o terço externo da seção mediana da manga. A seção apical e o terço interno da porção mediana, mais próxima ao caroço, foram as porções mais ácidas e menos doces.

Pode-se concluir que os frutos avaliados apresentaram características superiores aos relatados na literatura e que a amostragem para avaliação do teor de sólidos solúveis da pinha deve incluir as frações basal, mediana e apical.

\section{REFERÊNCIAS BIBLIOGRÁFICAS}

ARAÚJO, M.T. Dispersão de sólidos solúveis em cebola. Horticultura Brasileira, Brasília, v.4, n.2, p.42, 1986. (Resumo 005).

BLEINROTH, E.W. Determinação do ponto de colheita. In: NETTO, A.G. Melão para exportação: procedimentos de colheita e pós-colheita. Brasília, MAARA/FRUPEX, 1994. p.11-21. (Série Publicações Técnicas).

CARMER, S.G., NYQUIST, W.E.; WALKER, W.M. Least significant differences for combined analyses of experiments with two- or three- factor treatment designs. Agronomy Journal, Madison, v.81, n.2, p.665-672, 1989.

CARVALHO, P.S. de; BEZERRA, J.E.F., LEDERMAN, I.E.; ALVES, M.A.; MELO NETO, M.L. de. Avaliação de genótipos de pinheira (Annona squamosa L.) no vale do rio Moxotó III- Características de crescimento e produção-1992 a 1997. Revista Brasileira de Fruticultura, Jaboticabal, v.22, p.27-30, 2000.

GRANGEIRO, L.C.; PEDROSA, J.F.; BEZERRA NETO, F; NEGREIROS, M.Z. de. Qualidade de híbridos de melão-amarelo em diferentes densidades de plantio. Horticultura Brasileira, Brasília, v.17, p.110-113, 1999.

MAIA, G.A.; MESQUITA FILHO, J.A.; BARROSO, M.A.T.; FIGUEIREDO, R.W. Características físicas e químicas da ata. Pesquisa Agropecuária Brasileira, Brasília, v.21, n.10, p.10731076, 1986.

MARTINSEN, P.; SCHAARE, P. Measuring soluble solids distribution in kiwifruit using near-infrared imaging spectroscopy. Postharvest Biology and Technology, v.14, p.271-281, 1998.

PINHEIRO, R.V.R.; MARTELETO, L.O.; SOUZA, A.C.G. de; CASALI, W.D.; CONDÉ, A.R. Produtividade e qualidade dos frutos de dez variedades de goiaba, em Visconde do Rio Branco, Minas Gerais, visando ao consumo ao natural e à industrialização. Revista Ceres, Viçosa, v.31, p.360-387, 1984.

SIMÃO, S.; PIMENTEL-GOMES, F. Açúcares e acidez: sua distribuição em torno da manga (Mangifera indica, L.). Revista de Agricultura, Piracicaba, v.71, n.1, p.3-12, 1996. 